
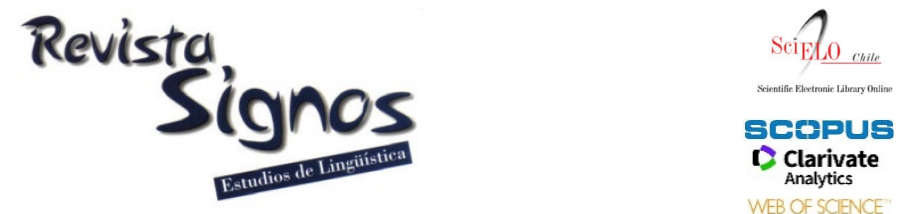

\title{
Atenuación en el discurso de los participantes no profesionales de los juicios orales. ¿Un caso de lenguaje débil? ${ }^{1}$
}

\author{
Mitigation in the speech of the non-professional participants \\ during trials. A case of powerless language?
}

Cristina Villalba Ibáñez

Universitat De VALĖNCIA / Universitat Jaume I ESPAÑA

cristina.villalba@uv.es

Recibido: 08-III-2020 / Aceptado: 14-VIII-2020

DOI: $10.4067 /$ S0718-09342020000300842

\section{Resumen}

El objetivo de este artículo es estudiar la manera en que se manifiesta la atenuación en los participantes no profesionales de los juicios orales. Tradicionalmente, se ha vinculado el empleo de recursos relacionados con la atenuación (como los hedges o las fórmulas de cortesía) con el lenguaje débil, pues las personas que usan estos recursos en su declaración limitan su compromiso con lo dicho y son percibidas como menos creíbles y menos inteligentes (Erickson, Lind, Johnson \& O'Barr, 1978). No obstante, tras analizar un corpus de 12 juicios orales españoles pertenecientes al juzgado de lo penal, se ha comprobado que el uso de estos y otros recursos que se asocian con la atenuación pueden ponerse al servicio de fines argumentativos. En este sentido, la reducción de la fuerza ilocutiva, del compromiso con lo dicho o el grado de imposición no siempre deben entenderse como casos de debilidad, sino como herramientas para satisfacer una meta comunicativa.

Palabras Clave: Atenuación, lenguaje débil, discurso débil, juicios orales, argumentación.

\section{Abstract}

The goal of this paper is to study the way in which the mitigation manifests itself in the lay participants speech during trials. Traditionally, the use of devices related to mitigation (such as hedges or politeness forms) has been linked to powerless language, since people who use these resources in their statements limit their commitment to what was said and are perceived as less credible and less intelligent (Erickson, Lind, Johnson \& O'Barr, 1978). However, after analysing a corpus of 12 Spanish oral trials 
from criminal court, it has been observed that the use of these and other devices related to mitigation can be used for other purposes related to argumentation. In this sense, the reduction of the ilocutive force, the commitment to what has been said or the degree of imposition should not always be understood as cases of powerless language, but as tools to satisfy a communicative goal.

Key Words: Mitigation, powerless language, powerless speech, trials, argumentation.

\section{INTRODUCCIÓN}

Los estudios sobre lingüística forense aplicados al análisis del discurso en sede judicial pueden clasificarse en tres tipos: aquellos que se centran en el análisis del discurso de los profesionales, los que se preocupan por la interacción entre profesional-lego y los que se focalizan en el discurso de los participantes no profesionales.

Dentro de este último, encontramos varios trabajos orientados a evaluar las impresiones que generan las declaraciones de testigos. Entre los primeros que siguen esta perspectiva de análisis, están los estudios de Bradac, Hemphill y Tardy (1981), Bradac y Mulac (1984) y Erickson et al. (1978). En ellos, se distinguen dos tipos de estilo discursivo o lenguaje: el lenguaje de poder y el lenguaje débil2 ${ }^{2}$. Este último es propio de las personas con bajo estatus y una posición jerárquica baja en los juicios orales. El lenguaje débil se caracteriza, a grandes rasgos, por el empleo de recursos que frecuentemente se relacionan con la atenuación, como aproximativos, difusores del significado (hedges), fórmulas corteses o marcadores de control del contacto. En contraste, el discurso de poder se caracteriza por la ausencia de estos elementos (Erickson et al., 1978).

A partir de este momento, parece que existe un consenso generalizado entre la aparición de los rasgos que se relacionan con el discurso débil y la generación de impresiones negativas sobre la credibilidad de la persona que tiene este estilo discursivo. En esta línea, podría inferirse que la ausencia de los recursos asociados al lenguaje débil sería deseable por parte de los participantes no profesionales en el proceso judicial para mostrarse como personas sinceras y fiables. Máxime si, cuando entran a declarar, se les informa de que tienen la obligación de decir la verdad y, en caso de no hacerlo, pueden ser acusados del delito de falso testimonio previsto en los artículos 458-462 del Código Penal español ${ }^{3}$.

Sin embargo, nuestra hipótesis sostiene que el uso de mecanismos de atenuación cumple un papel destacado en el discurso de los participantes no profesionales, ya que pueden emplearse estratégicamente para proyectar una imagen positiva sobre sí mismos y cuidar las relaciones con el otro. En esta línea, nuestro objetivo en este trabajo es doble. En primer lugar, se centra en investigar y describir el uso que hacen de la atenuación los participantes no profesionales. En segundo lugar, busca valorar en 
qué medida el uso de estos mecanismos lingüísticos se vincula al escaso poder que tienen los participantes no profesionales en el juicio oral, como ha sostenido tradicionalmente la bibliografía, o si, por el contrario, su uso puede vincularse a una finalidad estratégica.

\section{Marco teórico}

\subsection{Lenguaje de poder y lenguaje débil}

Los estudios sobre estilos discursivos están asociados al surgimiento de la sociolingüística y al reconocimiento de la influencia de factores contextuales en el uso que se hace del lenguaje. Entre los primeros trabajos que se centran en la evaluación de las impresiones y la influencia del estilo comunicativo en el destinatario, encontramos trabajos como el de Lambert, Hodgson, Gardner y Fillenbaum (1960) y Giles (1971). Posteriormente, investigaciones como la de Erickson et al. (1978) postulan un nuevo enfoque dentro de la lingüística forense, pues se trata de evaluar la influencia de los estilos comunicativos de los participantes no profesionales y las impresiones que generan en un contexto concreto: la sala del juzgado.

Tras escuchar alrededor de 150 horas de grabación, Erickson et al. (1978) llegaron a la conclusión de que las personas con bajo poder social y un estatus jerárquico bajo en los juicios orales emplean intensificadores ('muy', 'de verdad', como en 'De verdad lo hice'), hedges ('algo', 'creo', 'supongo', etc.), formas especialmente formales de la gramática ${ }^{4}$, formas de duda ('uh', 'bueno', ‘¿sabes?’, etc.), gestos (por ejemplo, acompañando con las manos expresiones como 'por allí'), formas relacionadas con la modalidad interrogativa (como el uso de una entonación ascendente propia de las preguntas en contextos declarativos) y formas corteses (como 'por favor' y 'gracias'). ${ }^{5}$ Todos estos elementos son marcadores de lenguaje débil, ya que su ausencia conlleva la realización de un discurso más asertivo, dominante y seguro (Grob, Meyers \& Schuh, 1997).

En varios experimentos llevados a cabo desde el campo de la psicología (a veces en colaboración con otras disciplinas, como el derecho) se ha observado que, tras exponer a los sujetos de los experimentos a textos (orales o escritos) con la presencia de marcadores de lenguaje débil y sin ellos, se valoran más negativamente los primeros. En consecuencia, los sujetos valoran a las personas que emplean el lenguaje débil como menos creíbles, menos competentes ( Erickson et al., 1978; Bradac et al., 1981; Bradac \& Mulac, 1984), con menor control sobre lo dicho y generan, en definitiva, opiniones más negativas (Hosman \& Siltanen, 2006).

Más recientemente, algunos investigadores como Durik, Britt, Reynolds y Storey (2008) empiezan a ser críticos con los estudios realizados hasta ahora, pues no han tenido en cuenta factores que pueden condicionar la interpretación sobre el uso que se hace de los marcadores del lenguaje débil en general y, particularmente, de los hedges. 
Así, se subraya la importancia de tener en cuenta el género discursivo y los conocimientos que tienen los participantes sobre este, pues únicamente teniendo en cuenta estos factores se puede hacer una interpretación adecuada de los marcadores de lenguaje débil y, más concretamente, de los recursos que negocian el compromiso epistémico con lo dicho.

\subsection{El fenómeno pragmático de la atenuación}

Entendemos por atenuación el uso estratégico de una serie de recursos lingüísticos motivado por unas necesidades de imagen con el fin de satisfacer una meta comunicativa. En esta línea, la atenuación:

"[p] ermite a los emisores formular un menor compromiso con lo dicho y así lograr más eficazmente las metas conversacionales de los participantes en el discurso. Se expresa a través de mecanismos de lenguaje vago que difuminan el contenido proposicional, de minimización de la cantidad o cualidad semánticas o directamente reduciendo la fuerza ilocutiva de los actos de habla." (Albelda \& Briz, 2020).

Dentro de los estudios de atenuación, uno de los elementos que primeramente captó el interés de los investigadores fue, precisamente, el uso de hedges (Lakoff, 1973). Estos elementos ayudan a hacer el significado difuso, aproximado, vago. A la luz de esta definición, podría parecer que lenguaje vago y hedges son sinónimos; sin embargo, la diferencia reside en que mientras que los recursos de lenguaje vago afectan directa y únicamente al contenido proposicional y no tienen consecuencias pragmáticas en la fuerza ilocutiva y la gestión de las imágenes, los hedges sí que operan más allá del contenido proposicional (Overstreet, 2011). A modo de ejemplo, en (1) el uso del aproximativo 'algo' afecta al contenido semántico, pero no reduce en ningún grado la aseveración o afecta en modo alguno a la relación entre los participantes. Por el contrario, en (2) el uso de 'algo' está orientado a reducir un reproche e intentar cuidar la relación que tiene el hablante con la persona que ha cocinado la sopa. Constituye, por tanto, un hedge, pues está al servicio de la atenuación ${ }^{6}$.

(1) La sopa castellana lleva algo de sal.

(2) Esta sopa está algo salada.

\subsubsection{Las funciones de la atenuación}

El uso de la atenuación se relaciona con la voluntad de atenuar posibles efectos negativos que pueda tener un enunciado o una acción y conseguir una serie de objetivos durante la comunicación (Fraser, 1980). En este sentido, la relación entre atenuación y argumentación es evidente. 
Tomemos el siguiente ejemplo por caso. En este juicio oral, se acusa al acusado (A) de haber presentado una denuncia falsa. El Ministerio Fiscal (MF) le enseña al acusado la denuncia que este presentó contra un local al día siguiente de que se produjeran los hechos y el acusado trata de alegar que no estaba en plenas facultades cuando la presentó y que los mossos d'esquadra ${ }^{7}$ no recogieron un relato fiel de lo sucedido.

(3a) MF: mire / es el folio 4 / si pasa al folio siguiente / ahí estará suu / su firma / A: sí / yo recuerdo / pero / traté de denunciar / de aquella manera / y ellos haberme- / haberme interpretado / de lo que ellos / más o menos / han querido /

CPP Juicio oral 4

En primer lugar, el acusado no dice abiertamente que presentó una denuncia, sino que explica que trató de hacerlo 'de aquella manera'; es decir, no especifica hasta qué punto logró interponer la denuncia (de ahí el verbo 'tratar') y, por el contexto, podemos deducir que esa denuncia la hizo torpemente o con poco éxito, pues estaba bajo el influjo del alcohol. El acusado reconoce haber interpuesto una denuncia, pero reduce el grado de certeza que tiene sobre la consecución y la fiabilidad de este hecho.

Mostrarse como una persona con escaso control sobre sus acciones en el día de autos es un atributo positivo para la imagen del acusado en este caso concreto, donde estar bajo la influencia del alcohol u otras sustancias puede operar como una circunstancia atenuante.

Por otro lado, en la misma declaración dice que los mossos d'esquadra interpretaron 'más o menos lo que han querido'; en otras palabras: los agentes no dieron un traslado fiel de su declaración. Esto es una acusación grave, pues los cuerpos de seguridad tienen que ofrecer un relato fiel de los hechos. Como hacer esta afirmación sin el aproximativo 'más o menos' puede hacer que su enunciado se convierta en un reproche y atentar severamente contra la imagen profesional de los agentes que redactaron la denuncia, decide servirse de este aproximativo. La atenuación, por tanto, se pone al servicio del cuidado de la imagen del otro, aunque esto, a su vez, también tenga consecuencias positivas para la propia imagen: el acusado se muestra como una persona respetuosa.

Veamos qué sucedería si desaparecieran los mecanismos de atenuación:

(3b) A: sí / yo recuerdo / pero / denuncié / y ellos interpretaron lo que han querido

Si contrastamos este enunciado con una versión libre de atenuantes, como la de (3b) el grado de compromiso con lo dicho aumenta, pero el precio es argumentativamente alto, pues supone reconocer abiertamente haber interpuesto una denuncia que ha resultado ser falsa y acusar a los mossos d'esquadra de realizar mal su trabajo. 


\subsubsection{Atenuación en contextos formales: el caso de los juicios orales}

La atenuación es un fenómeno pragmático que está íntimamente relacionado con el registro y el género (Albelda, 2018; Briz \& Albelda, 2013; Figueras, 2018). Las características de la situación comunicativa y los rasgos que concretan el género en relación con la imagen que se espera de los participantes condicionan no solo la frecuencia, sino también las funciones y los recursos que emplearán los participantes para atenuar. Es por ello que, además de comprender los atributos que cada rol tiene durante el desarrollo del juicio, es preciso caracterizar la situación comunicativa.

Los juicios orales son espacios destinados a resolver un conflicto dentro de un marco institucional, que reviste de formalidad el acto. Esta situación de conflicto en la que conviven distintas versiones de los hechos hace que la atenuación juegue un papel destacado en la argumentación y en la interacción entre los participantes.

En este espacio conviven participantes profesionales (como jueces y abogados) y participantes no profesionales, como acusados, testigos o peritos. Generalmente, estos participantes perciben el juzgado como un espacio de interacción no cotidiano y no tienen una formación profunda en derecho. Además, el hecho de que solo puedan intervenir cuando el juez lo indique o los letrados les pregunten, da cuenta de la baja posición jerárquica que ocupan los legos en contraste con los participantes profesionales.

Aunque encontramos algunos trabajos que analizan el uso de la atenuación en profesionales del derecho (Taranilla, 2009; Villalba, 2017), esta investigación se sitúa en la línea de trabajos clásicos (Danet, 1980; Martinovski, 2006), donde el foco de interés se centra en los participantes no profesionales. Así, en nuestro caso nos interesamos por estudiar qué elementos lingüísticos atenuantes concretos utilizan los legos y analizar si verdaderamente se trata de casos de lenguaje débil o si hay una función detrás de su empleo que justifique su aparición.

\section{Metodología}

Para la elaboración de esta investigación, se ha seguido un enfoque cuantitativo y cualitativo basado en el análisis de corpus. En las siguientes líneas se detallan las características del corpus, así como las categorías que se han tenido en cuenta para desarrollar el análisis.

\subsection{Corpus}

Se ha partido de un corpus de 12 juicios orales españoles (77.774 palabras) celebrados en juzgados de lo penal. En concreto, el corpus se compone de 10 juicios orales procedentes del Corpus de Procesos Penales (Taranilla, 2011b) y 2 juicios orales del Corpus Val.Es.Co. del Discurso Jurídico (inédito) ${ }^{8}$. Los juzgados de lo penal se 
caracterizan por ser una de las jurisdicciones donde intervienen participantes no profesionales (como testigos y peritos) con más frecuencia. Como nuestro propósito es, precisamente, investigar el uso que se hace de la atenuación entre los participantes no profesionales, la elección de la jurisdicción se alinea con los objetivos de este trabajo.

\subsection{Identificación de los casos de atenuación y variables de análisis}

Se ha tomado como referencia la ficha para el análisis de la atenuación de Albelda, Briz, Cestero, Kotwica y Villalba (2014) para la selección de variables que se han tenido en cuenta en este estudio. Esta ficha ha sido validada en distintos corpus y variedades del español, y ha probado ser de utilidad (por citar algunos ejemplos, véanse los trabajos de Contreras \& Zhao, 2017; Flores Treviño, 2017; Samper, 2017; Hernández Flores \& Rodríguez Tembrás, 2018). Además, esta ficha aúna las principales aportaciones de los teóricos de la atenuación y proporciona al analista un catálogo de formas que pueden ayudar a realizar el análisis.

Evidentemente, en tanto fenómeno pragmático, el reconocimiento de la atenuación no debe quedarse solo en la forma, sino que debe evaluarse contexto a contexto (Caffi, 1999; Briz \& Albelda, 2013). En nuestro caso, la identificación de los casos de atenuación se ha acompañado de la aplicación de tres pruebas de reconocimiento propuestas en Villalba (2018): la prueba de la ausencia, la conmutación y la solidaridad.

- La 'prueba de la ausencia' consiste en eliminar el elemento que consideramos que codifica atenuación y observar si se producen cambios en la fuerza ilocutiva o en la gestión de las imágenes. Si la fuerza ilocutiva se incrementa o las imágenes pueden verse potencialmente amenazadas, estaremos ante un caso de atenuación.

- La 'prueba de conmutación' se utiliza cuando no es posible eliminar el elemento del enunciado $y$, en su lugar, debe sustituirse por otra(s) forma(s) con valores similares. A continuación, estas posibilidades se ordenan en una escala donde se identifique la forma neutra. Si la forma del enunciado queda por debajo en esa escala y, en comparación con la forma neutra, se observa una reducción en la fuerza ilocutiva o afecta a la gestión de las imágenes, se tratará de un caso de atenuación.

- Finalmente, la 'prueba de solidaridad' es la menos robusta, pero también puede ser de ayuda. Esta prueba parte de la idea de que la atenuación no suele manifestarse de manera aislada, sino que suelen aparecer varios mecanismos con valores atenuantes. Así, cuando se tienen dudas acerca de si un mecanismo desarrolla o no una función atenuante y está rodeado de formas que sí lo hacen, lo más probable es que el elemento que plantea dudas codifique atenuación. 
Una vez que se identificaron los casos de atenuación, se sometieron a un análisis que se estructuró a partir de dos variables: el mecanismo de atenuación y el rol del participante.

\subsubsection{Mecanismos de atenuación}

La ficha del Albelda et a. (2014) cuenta con 22 categorías que recogen los principales mecanismos de atenuación en español. Entre estos mecanismos se encuentran: a) el empleo de modificadores morfológicos internos (sufijos diminutivos); b) modificadores externos (cuantificadores minimizadores, aproximativos o difusores significativos proposicionales o extraproposicionales); c) términos o expresiones más suaves en el contenido significativo (como lítotes o eufemismos); d) extranjerismos; e) usos modalizados de los tiempos verbales; f) verbos, construcciones verbales y partículas discursivas modales que expresan opinión en forma de duda o de probabilidad; g) verbos, construcciones verbales y partículas discursivas que expresan fingimiento de incertidumbre, de incompetencia o de ignorancia; h) construcciones acotadoras de la opinión a la propia persona o a un determinado ámbito; i) peticiones, preguntas, mandatos u órdenes expresadas de forma indirecta; j) expresiones de disculpa; k) estructuras sintácticas que restringen el acto de habla; l) construcciones justificadoras o de excusa; m) elipsis de la conclusión, estructuras suspendidas o estructuras truncadas; n) impersonalización (mediante la ocultación del agente y a través del recurso al estilo directo); ñ) movimiento de reformulación; o) concesividad; p) partículas discursivas modales de objetivación (evidenciales); q) partículas discursivas y expresiones de control de contacto con el interlocutor; r) formas de tratamiento y fórmulas apelativas; s) elementos prosódicos, paralingüísticos o gestuales; y t) otros procedimientos (que engloban aquellos fenómenos no clasificables en las categorías anteriores).

\subsubsection{Rol del participante}

Dentro de los participantes no profesionales, pueden distinguirse distintos grupos en función de varios factores como el motivo que les lleva a prestar declaración, los derechos y obligaciones que tienen en el momento de declarar o los conocimientos que poseen. En nuestro caso, se distinguen cuatro grupos de participantes: acusados, testigos, testigos-agentes de las fuerzas de seguridad y peritos ${ }^{9}$.

Los acusados son las personas que (presuntamente) han cometido el acto por el que se ha iniciado el proceso judicial. A diferencia del resto de los participantes, tienen el derecho a no declarar y a la última palabra, una vez que han declarado todas las partes y se va a dar por concluido el juicio oral. En términos argumentativos, su declaración se centra en hacer un relato de los hechos que demuestre su inocencia o menor grado de culpabilidad. 
Los testigos son aquellas personas que ofrecen su testimonio sobre lo sucedido y su declaración puede ir en beneficio o detrimento del acusado. Cuando intervienen los participantes no profesionales, como es el caso de los testigos, se les recuerda que tienen la obligación de declarar y de decir la verdad porque, en caso de no hacerlo, podrían incurrir en un delito de falso testimonio. En tanto conocedores (parciales) de los hechos, su función consiste en contestar a las preguntas que los abogados o el juez quieran formular.

También pueden comparecer en calidad de testigos agentes de las fuerzas de seguridad, como policías locales, policías nacionales o miembros de policías autonómicas como los mossos d'esquadra, por citar algunos de los ejemplos que se encuentran en nuestro corpus. Su comparecencia en los juzgados de lo penal es recurrente, pues hay delitos que, o bien se cometen en su presencia, o bien acuden de forma inmediata tras su comisión e intervienen en las primeras fases del proceso judicial a partir de la elaboración de denuncias o atestados (Fuentes González, 2014). Consideramos que los testigos-agentes son una clase distinta de testigo precisamente por la asiduidad con la que comparecen ante el juzgado, por los conocimientos que tienen sobre el campo del derecho y por la posibilidad de preparar la declaración a partir de lo que dice el atestado, que en muchos casos han redactado los propios declarantes.

Por último, los peritos son testigos expertos, profesionales en distintas áreas (medicina, psicología, lingüística...) que elaboran un informe acerca de algún aspecto que pueda aportar más información sobre los hechos que se van a juzgar. Su función durante el juicio oral se concreta en ratificar su informe y contestar a las preguntas que le hagan sobre el informe o en su calidad de experto.

\section{Resultados}

En total, se han registrado 124 casos de atenuación en el discurso de los participantes no profesionales, tal y como se muestra en la Tabla $1{ }^{10}$. 
Tabla 1. Recuento de frecuencias de los principales mecanismos de atenuación empleados.

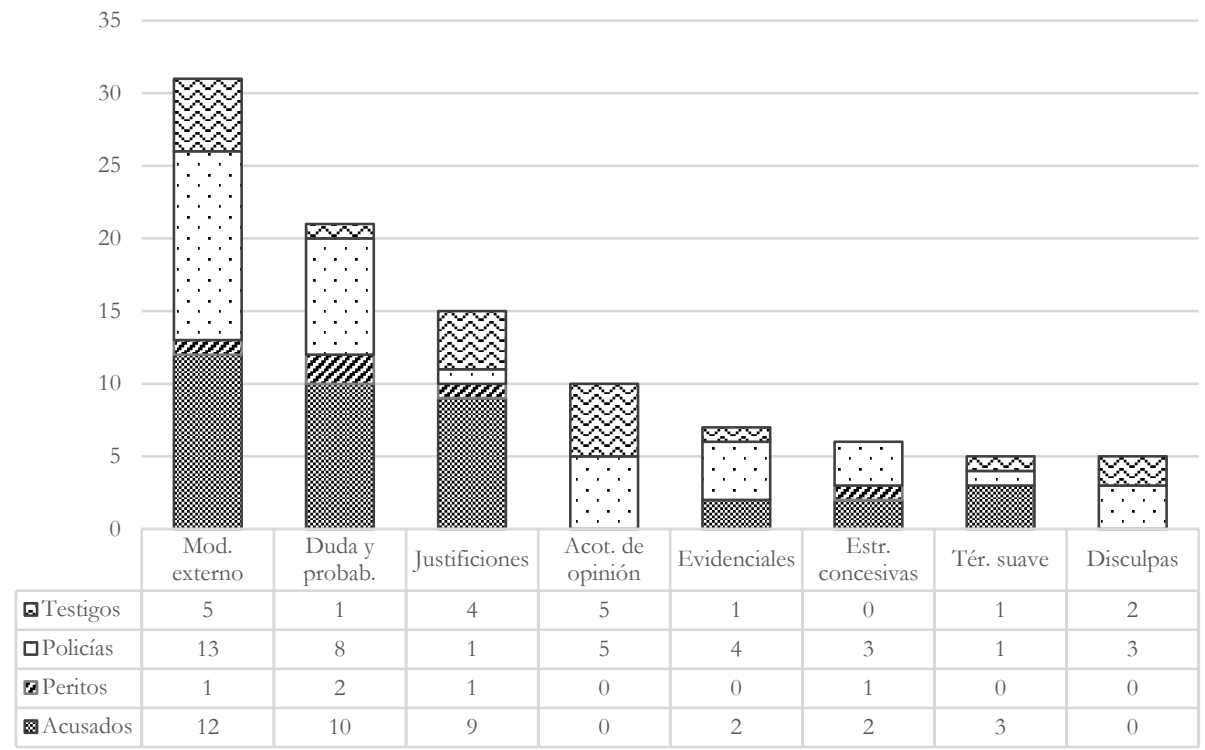

Destaca el uso de modificadores externos que, con 31 casos, es el recurso más frecuente seguido de los verbos, construcciones verbales y partículas discursivas modales que expresan opinión en forma de duda o de probabilidad; las justificaciones; las construcciones acotadoras de la opinión a la propia persona o a un determinado ámbito; los recursos evidenciales; las estructuras concesivo-opositivas; los términos suaves y las disculpas.

Al comparar estos resultados con otros trabajos centrados en el análisis de la atenuación en figuras profesionales (Villalba, 2017), vemos que los resultados son similares salvo en dos aspectos. Los mecanismos de impersonalidad son el recurso atenuante más empleado entre los profesionales del derecho durante los juicios orales y este recurso apenas se ha registrado en esta investigación. En contraste, el recurso de acotar la opinión al terreno de lo personal es mucho más frecuente en este análisis que en el de Villalba (2017). Ambos recursos están orientados a presentar una estrategia argumentativa diferente: la impersonalidad persigue el distanciamiento del hablante del discurso con el fin de crear un mensaje más objetivo y más fácilmente aceptable por la audiencia. En contraste, cuando se acota al terreno de lo personal, el hablante se reivindica como responsable del enunciado, pero esta responsabilidad se reduce a su propia experiencia. Nos referimos a enunciados como el del ejemplo (4), donde el hablante evita comprometerse sin ambages con la afirmación a la pregunta que se plantea y limita la certeza sobre los hechos a lo que ha conocido a partir de sus vivencias. Este recurso va a ser empleado especialmente por las personas que 
presencian los hechos y tratan de hacer un retrato fiel de lo sucedido (fuerzas de seguridad y testigos).

(4) D: bueno / .. e:: / este señor / se quedó ingresado / en el centro Talanta / ¿no? / allí se lo quedaron /

M1: por lo que yo conozco sí /

CPP Juicio 8

En definitiva, este contraste entre los mecanismos refrenda el hecho de que el uso de los mecanismos de atenuación está íntimamente ligado con el género y, en especial, con el rol que se desempeña cada participante.

En relación con este último punto, el análisis de los datos revela que, teniendo en cuenta el número de palabras emitido por cada participante en el juicio oral, los agentes de las fuerzas de seguridad son los que más recursos de atenuación emplean, seguidos de los acusados, los peritos y, en último lugar, los testigos.

Tabla 2. Porcentaje de mecanismos de atenuación respecto al número de palabras.

\begin{tabular}{|l|c|c|c|c|}
\cline { 2 - 5 } \multicolumn{1}{c|}{} & Seguridad & Acusado & Testigos & Peritos \\
\hline Elementos atenuantes & 38 & 38 & 19 & 5 \\
\hline Número de palabras & 7109 & 8233 & 9930 & 1819 \\
\hline $\begin{array}{l}\text { Porcentaje de mecanismos atenuantes respecto al } \\
\text { número de palabras }\end{array}$ & 0,53 & 0,46 & 0,19 & 0,27 \\
\hline
\end{tabular}

A continuación, reflexionaremos sobre el rol que desempeña cada participante, así como la posible familiaridad o formación que hayan podido recibir en relación con la declaración en el juzgado como factores relacionados con el uso de la atenuación.

\subsection{Agentes de las fuerzas de seguridad}

Los agentes de las fuerzas de seguridad, junto con los acusados, son los participantes que más mecanismos de atenuación emplean en sus declaraciones y destacan por la variedad de recursos utilizados. Hay que tener en cuenta que los policías tienen un mayor contacto con el aparato jurídico y en muchos casos pueden haber recibido asesoramiento o formación específica para declarar en el juzgado. En este sentido, la mayor presencia de recursos atenuantes en comparación con otros participantes como los testigos, que desarrollan un rol muy similar, se explica por la mayor o menor cotidianidad del acto y por la posible instrucción recibida para enfrenarse a estas situaciones.

A los policías que comparecen como testigos se les suele preguntar por lo que aparece en el atestado policial o en la denuncia que, en algunas ocasiones, han redactado ellos mismos hace algún tiempo. En esta línea, el interrogatorio se orienta a comprobar si hay inconsistencias entre lo dicho en el atestado y lo que manifiesta el agente de las fuerzas de seguridad en la sala. Por su parte, los agentes se esfuerzan por 
mostrar que actuaron de acuerdo con lo que se espera de su cargo y por elaborar un relato creíble, haciendo uso de todos los recursos a su alcance, como sucede en (5):

(5) MF: sí / con la venia / ¿cuál fue su intervención / el 1 de junio del 2008 / a las 5 y media de la tarde / aproximadamente / en la calle San Pol / de Badalona? /

M3: pues nos avisaron / de que parecía ser que habían salido unos señores / de una zona de obra / y que llevaban un- / un carro / y que di- / bueno / que habían- / por lo visto / habían cogido una serie de objetos / .. nosotros fuimos aa / por la zona / localizamos a dos personas / e:: / coincidía con la descripción / que había dao el testigo / yy / bueno / llevaban / precisamente llevaban un carro / llevaban diferentees herramientas / cizallas / tenazas /

CPP Juicio 5

El mosso d'esquadra está relatando por qué él y sus compañeros se dirigieron a dos personas como posibles autores de un delito de robo en unas obras. El uso de la estructura 'parecía ser que' y el evidencial 'por lo visto' se encaminan a marcar que el origen de la información que va a continuación no procede del hablante, sino de otra persona (un testigo) que informa de esta situación. Esta desresponsabilización sobre lo dicho, creando distancia sobre sus palabras, es una manera de no comprometerse con la veracidad de algo de lo que no puede estar totalmente seguro (pues no lo presenció directamente) y de legitimar su actuación, pues no pararon a cualquier persona basándose en prejuicios, sino en lo que había relatado un testigo.

Por último, resulta llamativo que, al igual que sucede con los testigos, en el discurso de los agentes de seguridad se observa la presencia de disculpas como recurso atenuador. Estas disculpas pueden estar orientadas a la autoprotección (cuando se producen autocorrecciones) o al cuidado de la imagen del otro, cuando se prevé o ya se ha producido una amenaza. Normalmente, esto sucede en situaciones en las que agentes o testigos roban el turno o contradicen a su interlocutor, como puede observarse en (6):

(6) D: con la venia Señoría/ su compañero (( ))/ que él salió detrás del $\rightarrow$ otro individuo y del coche/ pero que usted se quedó haciendo un servicio humanitario

T4: perdón yo no me quedé en ningún servicio humanitario

PVA 752-754

En relación con lo observado, puede concluirse que la atenuación en el discurso de los agentes de seguridad es la más variada y esto puede estar relacionado con el hecho de que la comparecencia en juicios no es algo extraño dentro del ejercicio de su profesión. Asimismo, el uso de la atenuación se encamina, como en el caso de los testigos, a mostrarse como personas creíbles y, en tanto profesionales, a mostrar que su actuación en el caso se hizo de manera objetiva y de acuerdo a lo establecido por la ley. 


\subsection{Atenuación en acusados}

A la luz de los datos, los acusados sienten preferencia por el empleo de modificadores externos, como sucede en el ejemplo (7).

(7) MF: ¿usted cobró alguna cantidad de dinero por esaas / por esos anuncios publicitarios / las visitas que a su vez se recibían en la página? /

PR: e:: / cobré poco / peroo / tampoco puedo asegurar ahora la cantidad exacta

CPP Juicio 9

El Ministerio Fiscal le pregunta al acusado si percibió algo de dinero por la publicidad que se mostraba en su página web, donde se ofrecían claves para acceder a plataformas de televisión de pago. Como existen registros, el acusado no puede negar este hecho, pero intenta matizar el grado de culpabilidad mediante el cuantificador minimizador 'poco'. De esta manera, autoprotege su imagen y tratar de obtener una sentencia favorable.

En las declaraciones de los acusados es frecuente que diversos mecanismos de atenuación aparecen juntos, como sucede en el siguiente ejemplo.

(8) MF: entonces / ¿por qué piensa que ha sido denunciada? /

EM: pues yo creo quee / porque Juan Javier pasaba por allí / en ese momentoo / tienen rencillas familiares / de hace mucho tiempo / Juan ha llevado una vida / no muy adecuada / pero la gente tiene una segunda oportunidad / la cogió / ha estado bien / y solamente pasaba por allí / y como nosotros fuimos / y su se- / el señor marido de esta señora / lo cogió por a- / yo estaba en casa de mi suegra / pero él lo con- / lo cogió por- / lo zarandeó

CPP Juicio 10

En los juicios orales se produce un enfrentamiento entre dos (o más) versiones de los hechos que son antagonistas y es tarea de los participantes expertos (letrados, fiscales y jueces) llegar a comprender lo sucedido a partir de las pruebas, como la declaración de los implicados. En este caso, la respuesta de la acusada ('yo creo que') a la pregunta del Ministerio Fiscal reduce el compromiso epistémico del razonamiento que va a presentar. Esta reducción muestra la voluntad de la acusada de contar la verdad dentro de los límites de sus conocimientos, ya que posteriormente dice que estaba en casa de su suegra (no presenció, por tanto, directamente la disputa). Si no hubiera introducido su declaración con el 'creo que', el fiscal podría haber puesto en entredicho toda su declaración, pues la acusada habría presentado como una verdad absoluta algo de lo que no podía tener suficiente certeza.

Seguidamente, la acusada pasa a explicar que su marido, Juan, ha llevado una vida 'no muy adecuada'. Esta lítote suaviza un término más fuerte, como podría ser el hecho de decir abiertamente que este llevaba 'una mala vida'. Es cierto que la pareja de la acusada no forma parte de lo que podríamos considerar propiamente la imagen de 
EM, pero sí que se relaciona con su territorio, con aquello que se relaciona directamente con el 'yo' y que tratamos de cuidar porque afecta, también, a nuestra imagen (Goffman, 1967). El uso del término suave sirve, en este caso, para distanciar del universo personal de la hablante un elemento negativo, como puede ser la mala vida de su compañero. En la misma línea, justo después de la lítote, se completa la estructura concesivo-opositiva. Esta construcción persigue el mismo objetivo: neutralizar o distanciar elementos negativos destacando, en este caso, que su pareja tiene una vida mejor.

Por último, tras hacer esta construcción positiva de su pareja, explica que este 'solamente' pasaba por allí y el otro encausado lo zarandeó. Es decir, que podría haber reiterado, como había hecho unos segundos antes, que su pareja pasaba por allí (la opción más neutra), pero elige restringir la acción para limitar las posibles interpretaciones negativas que se pudieran inferir (por ejemplo, pasaba por allí insultando, provocando al otro acusado, etc.).

A partir de los datos del corpus y los ejemplos presentados, puede concluirse que la atenuación en el discurso de los acusados está al servicio de construir una imagen positiva, tanto de sí mismos como de aquellos elementos que están ligados al 'yo', y reducir los aspectos negativos. No hay que perder de vista que el discurso de los acusados va a ser cuestionado por la Fiscalía y los abogados de la acusación particular (si los hubiere), por lo que la atenuación de lo que se dice o la reducción del compromiso epistémico puede estar encaminadas a hacer más aceptable su propio discurso.

\subsection{Atenuación en testigos}

El impacto que tiene la declaración de los testigos en el juicio oral sobre su propia vida es menor que en el caso de los acusados. De ahí que, pese a contar con un mayor número de palabras en el corpus, la cantidad de mecanismos de atenuación presentes sea menor.

La atenuación en testigos se caracteriza por el empleo de modificadores externos (al igual que el resto de participantes), acotadores de la opinión y justificaciones y excusas. Veamos algunos ejemplos como los de (9) y (10).

(9)

$\mathrm{J}:$ vamos $\downarrow$ que no vio nada/ no se ente[ró]

T1: $\quad$ [no yo] oía GRITOS $\uparrow$ eel policía eraa $\mathrm{mm}$ la ve- la ver- la verdad es que sea un poco grosero porque no tenía tampoco educación/ porque yo bajé para enterarme de las cosas y tampoco me contestó a nada $\downarrow$ no $\mathrm{mm} /$ era un poco grosero

PVB 581-585 
En este juicio, el marido de la testigo ha denunciado a un policía por abuso de autoridad. La declaración de la testigo se orienta a apoyar la tesis de que el policía no se comportó correctamente. La testigo podría haber dicho que el policía había sido grosero. Sin embargo, hacer un reproche abierto podría llevar a pensar que su declaración es partidista y, por tanto, menos creíble. Para evitarlo, la testigo reduce el contenido negativo de su amenaza mediante el cuantificador 'un poco' y ofrece justificaciones orientadas a mostrar que existe una base más o menos objetiva para llegar a esa conclusión ('porque tampoco tenía educación, porque bajé para enterarme de las cosas y tampoco me contestó a nada'). Así, mediante el uso de mecanismos de atenuación trata de proyectar una imagen de persona razonable y creíble para que su visión sobre lo sucedido sea aceptada.

En otras ocasiones, el uso de la atenuación va encaminada a ser lo más fiel posible a la realidad y, al mismo tiempo, evitar que se ponga en entredicho la propia declaración. Es lo que sucede en (9), donde la testigo MT primero niega rotundamente la pregunta del abogado de la defensa y, a continuación, reformula para restringir la certeza sobre lo dicho al ámbito del conocimiento personal ('que yo sepa no').

(10) D: de acuerdo / pregunta / ¿esa comprobación / se hizo en algún momento en sede policial o judicial / o ante un notario? /

MT: no / que yo sepa no / no sé si luego la policía lo pudo comprobar / pero como esas claves son cambiantes / es posible que cuando haya llegado la policía (...) pues no lo haya comprobado / pero sí que es verdad que nadie me lo-/ lo confirma / vamos

CPP Juicio 9

En definitiva, la atenuación en el discurso de los testigos tiene una doble orientación. Por una parte está encaminada a proteger la propia imagen con el fin de legitimar su propio discurso y mostrarse como personas creíbles y, por otro lado, se asocia a la voluntad de ser lo más fieles posibles a la verdad. No hay que olvidar, como ya se ha mencionado, que lo primero que se les dice a los testigos al entrar en la sala es que tienen la obligación de decir la verdad o incurrirían en un delito de falso testimonio.

\subsection{Peritos}

En nuestro corpus de 12 juicios orales solo comparecen 6 peritos. Esto explica en parte por qué el número absoluto de recursos empleados por estos participantes es inferior al resto. Sus recursos se relacionan con el registro formal y, más concretamente, con los característicos del ámbito académico. Es lo que sucede con el uso de los mecanismos de impersonalidad, como sucede en (10).

(10) P1: e:: / este informe está / ¿sí? / está hecho según el artículo 140 de la Ley de Pro- / de Propiedad Intelectual / y en el quee hay dos tasaciones / yy a través de 
este artículo / pues se- / se intenta valorar / e:: / por un lado / e:: / la remuneración que se hubiera obtenido / sii las personas que haan / que se han introducido en esa página / se hubieran dado de alta como clientes / y por otro / el de la pérdida de beneficio que se ha dejado dee / de tener / porquee esas personas / pues / e:: / no han sido clientes /

CPP Juicio 9

La perito está explicando los objetivos del informe de tasación que ha elaborado para el caso que se está juzgando. Podría haber utilizado la primera persona del singular, pues es ella quien firma el informe $y$, por tanto, quien se responsabiliza de la veracidad sobre lo dicho. No obstante, recurre a una construcción de pasiva refleja que le permite desfocalizar al agente que lleva a cabo la valoración. Al igual que sucede en los textos académicos, esta estrategia le permite presentar los datos de manera más objetiva, prevenir posibles cuestionamientos en su razonamiento y ganar la credibilidad de sus interlocutores.

Asimismo, el verbo 'intentar' (un modificador externo) actúa en el mismo sentido, pues reduce el compromiso con lo dicho para mostrar modestia y prevenir una pérdida de imagen si, a la luz de las pruebas practicadas en el juicio, los datos del informe necesitaran ser modificados.

Tradicionalmente, el empleo de estructuras no agentivas se ha destacado como uno de los mecanismos estrella para codificar atenuación en distintos géneros $\mathrm{y}$, en particular, en el ámbito jurídico (Martinovski, 2006; Taranilla, 2011a; Villalba, 2012, 2017). Sin embargo, en nuestro corpus solo encontramos 3 casos: dos emitidos por peritos a partir de una construcción con 'se' y uno emitido por un policía, en el que utiliza un tú impersonal (propio del registro coloquial). Estos resultados, en la línea de lo señalado a lo largo de este apartado, apuntan a la importancia de los roles discursivos y sus atribuciones dentro del género, pues determinan, en última instancia, la frecuencia y el tipo de recursos que se van a emplear.

\section{CONCLUSIONES}

El análisis realizado a lo largo de esta investigación revela que el uso de la atenuación en los participantes profesionales es complejo. Al contrario de las hipótesis establecidas por autores como Erickson et al. (1978) o Bradac et al. (1981), el uso de recursos atenuantes no siempre debe entenderse como un rasgo de lenguaje débil. Nuestro análisis del corpus muestra que la atenuación se pone frecuentemente al servicio de la argumentación de los participantes para satisfacer distintas metas discursivas. Así, todos los participantes coinciden en utilizar la atenuación para satisfacer unas necesidades de imagen, generalmente orientadas a proyectar una imagen favorable de sí mismos, de su actuación o de su investigación, y pueden ser una herramienta poderosa para dotar de credibilidad a su discurso. 
En el discurso de los acusados, la atenuación ayuda, además, a mitigar los aspectos negativos que puedan afectar a la causa por la que comparecen. Como su discurso va a ser cuestionado, también aparecen recursos que reducen del compromiso epistémico; sin embargo, su empleo no se justifica necesariamente con la falta de certeza, sino que puede emplearse para hacer más aceptable su propio discurso.

Los testigos destacan por ser los que menos recursos de atenuación emplean, pese a ser los participantes no profesionales que más hablan. Probablemente, esto se deba al hecho de que se les convoca a declarar por los conocimientos que tienen sobre unos hechos. En esta línea, la atenuación se convierte en un recurso para mostrarse creíbles y ofrecer un relato lo más fiel posible de lo sucedido.

En cuanto a los peritos, los recursos empleados (entre los que destaca la impersonalidad) se relacionan con aquellos que podríamos encontrar en los discursos académicos. Al igual que en estos contextos, los peritos usan la atenuación para hacer más aceptables los razonamientos de su informe.

Por último, los agentes de las fuerzas de seguridad son los que más frecuentemente atenúan y mayor variedad de recursos manifiestan. En su caso, el rol profesional también está en juego y tiene un impacto directo en el uso que se hacen los agentes de este mecanismo.

En conclusión, parece que los estudios sobre lenguaje de poder y el lenguaje débil tomaron una serie de formas lingüísticas que, ciertamente, pueden limitar el grado de compromiso que establece el hablante con lo dicho. No obstante, estos mecanismos requieren una reflexión más profunda de carácter lingüístico por parte del analista. En esta investigación se ha visto que recursos asociados a la limitación del compromiso epistémico o que desarrollaban valores aproximativos no necesariamente (o únicamente) reducen la credibilidad, sino que podían estar al servicio de estrategias argumentativas más o menos complejas. Además, el uso de estas formas, que se ha asociado tradicionalmente a participantes con un estatus de poder bajo en la sala, se manifiestan en nuestro corpus preferentemente en boca de participantes que, sin llegar a ser profesionales del derecho, tienen un contacto más directo con el aparato jurídico. En este sentido, es necesario replantearse la definición de lenguaje débil y que los estudios que aborden las impresiones que generan los mecanismos lingüísticos asociados a los distintos tipos de estilos discursivos tengan en cuenta los posibles valores pragmáticos asociados.

\section{REFERENCIAS BIBLIOGRÁFICAS}

Albelda, M. (2018). La variación genérico-discursiva de la atenuación como resultado de la variación de la imagen. Spanish in Context, 15(2), 346-368.

Albelda, M. \& Briz, A. (2020). Atenuación e intensificación. En M. a V. Escandell, A. Ahern \& J. Amenós Pons (Eds.), Pragmática. Madrid: Akal. 
Albelda, M., Briz, A., Cestero, A. M., Kotwica, D. \& Villalba, C. (2014). Ficha metodológica para el análisis pragmático de la atenuación en corpus discursivos del español. (ES.POR.ATENUACIÓN). Oralia, 17, 7-62.

Bradac, J. J. \& Mulac, A. (1984). A molecular view of powerful and powerless speech styles: Attributional consequences of specific language features and communicator intentions. Communication Monographs, 51(4), 307-319.

Bradac, J. J., Hemphill, M. R. \& Tardy, C. H. (1981). Language style on trial: Effects of powerful and powerless speech upon judgments of victims and villains. Western Journal of Speech Communication, 45(4), 327-341.

Briz, A. \& Albelda, M. (2013). Una propuesta teórica y metodológica para el análisis de la atenuación lingüística en español y portugués. La base de un proyecto común (ES.POR.ATENUACIÓN). Onomazéin, 28, 288-319.

Caffi, C. (1999). On mitigation. Journal of Pragmatics, 31, 881-909.

Contreras, J. \& Zhao, L. (2017). Análisis contrastivo de estrategias de atenuación en un corpus de correos electrónicos españoles, alemanes y chinos en Atenuación e intensificación en géneros discursivos. En W. Mihatsch \& M. Albelda (Eds.), Atenuación e intensificación en géneros discursivos (pp. 205-220). Madrid/Fráncfort: Iberoamericana Vervuert .

Cortés, L. (2019). Un polo “perverso" del lenguaje vago: El enmascaramiento en el discurso político. Normas, 9(1), 37-50.

Danet, B. (1980). Language in the legal process. Law \& Society Review, 14(3), 445-564.

Durik, A. M., Britt, M. A., Reynolds, R. \& Storey, J. (2008). The effects of hedges in persuasive arguments: A nuanced analysis of language. Journal of Language and Social Psychology, 27(3), 217-234.

Erickson, B., Lind, E. A., Johnson, B. C. \& O’Barr, W. M. (1978). Speech style and impression formation in a court setting: The effects of powerful and powerless speech. Journal of Experimental Social Psychology, 14(3), 266-279.

Figueras, C. (2018). Atenuación, género discursivo e imagen. Spanish in Context, 15(2), 258-280.

Flores Treviño, M. E. (2017). La atenuación y los marcadores de foco de exclusión en los corpus: PRESEEA-Mty / AMERESCO-Méx.Mty. Normas, 7(1), 19-32.

Fraser, B. (1980). Conversational mitigation. Journal of Pragmatics, 4, 341-350.

Fuentes González, M. (2014). El interrogatorio de policías como testigos y peritos. Ciencia policial: Revista del Instituto de Estudios de Policía, 125, 131-148. 
Giles, H. (1971). Patterns of evaluation to R. P., South Welsh and Somerset accented speech. British Journal of Social and Clinical Psychology, 10, 280-281.

Goffman, E. (1967). Interaction ritual: Essays on face-to-face interaction. Chicago: Aldine.

Grob, L. M., Meyers, R. A. \& Schuh, R. (1997). Powerful/powerless language use in group interactions: Sex differences or similarities? Communication Quarterly, 45(3), 282-303.

Hernández Flores, N. \& Rodríguez Tembrás, V. (2018). Lo que se debe hacer es cambiar un poco el estilo de vida. Estrategias de atenuación en el consejo médico. Spanish in Context, 15(2), 325-345.

Hosman, L. A. \& Siltanen, S. A. (2006). Powerful and powerless language forms: Their consequences for impression formation. Journal of Language and Social Psycology, 24(1), 33-46.

Lakoff, G. (1973). Hedges: A study in meaning criteria and the logic of fuzzy concepts. Journal of Philosophical Logic, 2, 458-507.

Lambert, W. E., Hodgson, R. C., Gardner, R. C. \& Fillenbaum, S. (1960). Evaluational reactions to spoken languages. The Journal of Abnormal and Social Psychology, $60(1), 44-51$.

Martinovski, B. (2006). A framework for the analysis of mitigation in courts: Toward a theory of mitigation. Journal of Pragmatics, 38, 2065-2086.

Overstreet, M. (2011). Vagueness and hedging. En G. Andersen \& K. Aijmer (Eds.), Pragmatics of Society (pp. 293-318). Berlín/Boston: De Gruyter.

Samper, M. (2017). Análisis sociolingüístico de la atenuación en el español de Las Palmas de Gran Canaria. En W. Mihatsch \& M. Albelda (Eds.), Atenuación e intensificación en géneros discursivos (pp. 153-168). Madrid/Fráncfort: Iberoamericana Vervuert.

Taranilla, R. (2009). La gestión de la propia imagen en las argumentaciones del Tribunal Constitucional: La función retórica de las estrategias de cortesía. Revista de Llengua i Dret, 52, 117-149.

Taranilla, R. (2011a). Análisis lingüístico de la transcripción del relato de los hechos en el interrogatorio policial. ELUA, 25, 101-134.

Taranilla, R. (2011b). La configuración narrativa en el proceso penal. Un análisis discursivo basado en corpus. Barcelona: Universitat de Barcelona [en línea]. Disponible en: http:/ /diposit.ub.edu/dspace/handle/2445/35052 
Taranilla, R. (2013). Aspectos metodológicos en la confección de un corpus jurídico. Consideraciones a propósito del Corpus de Procesos Penales. Revista de Investigación Lingüística, 16, 311-341.

Villalba, C. (2012). La impersonalidad como recurso atenuante en los juicios orales. En A. Cabedo, M. J. Aguilar \& E. López-Navarro (Eds.), Estudios de lingüística: Investigaciones, propuestas y aplicaciones (pp. 121-131) [en línea]. Disponible en: http://www.uv.es/canea/archivos/Estudios_linguistica_2013.pdf

Villalba, C. (2016). Actividades de imagen, atenuación e impersonalidad en los juicios orales. Valencia: Universitat de València.

Villalba, C. (2017). Actividades de imagen, atenuación e impersonalidad. Un estudio a partir de juicios orales españoles. Fráncfort: Peter Lang.

Villalba, C. (2018). Atenuación: Algunas claves metodológicas para su análisis. Normas, 8(1), 306-316.

\section{NOTAS}

1 Esta investigación se enmarca dentro del Proyecto ES.VAG.ATENUACIÓN ("La atenuación pragmática en su variación genérica: géneros discursivos escritos y orales en el español de España y América” MINECO FFI2016-75249-P).

2 Powerful speech y powerless speech en inglés. Traducción propia.

${ }^{3}$ Esta fórmula no se aplica a los acusados, que pueden negarse incluso a declarar si consideran que ello puede beneficiar la construcción de su defensa.

${ }^{4}$ Desafortunadamente, Erickson et al. (1978) no proporcionan ejemplos ni especifican a qué usos formales de la gramática se refieren.

${ }^{5}$ Estos ejemplos (procedentes de Erickson et al., 1978: 267) han sido traducidos por la autora.

${ }^{6}$ Véase Cortés (2019) para una reflexión más elaborada sobre el uso del lenguaje vago en el discurso político.

${ }^{7}$ Los Mossos d'Esquadra es el nombre de la policía autonómica de Cataluña.

${ }^{8}$ El Corpus de Procesos Penales (CPP) cuenta con diez grabaciones de juicios orales recopilados en los juzgados de Barcelona entre 2009 y 2010. Para más información sobre las características de este corpus, recomendamos consultar Taranilla (2013). Por lo que respecta a las dos grabaciones procedentes de Corpus Val.Es.Co. del Discurso Jurídico, las grabaciones se recopilaron en los juzgados de Valencia en 2011. Si se desea conocer más información sobre este corpus, se puede consultar en Villalba (2016: 80-89). 
${ }^{9}$ En nuestro corpus, los denunciantes o querellantes o bien se han insertado dentro del grupo de acusados, puesto que también han sido denunciados por la otra parte, o bien se insertan como testigos, pues son llamados a declarar durante la fase de pruebas testifical por los abogados de la parte activa.

10 Para facilitar la visualización, se han omitido de la tabla aquellos casos cuya frecuencia era inferior a 5, como sucede con el uso de mecanismos de impersonalidad, tiempos verbales dislocados y recursos para fingir ignorancia (4 casos); las reformulaciones (3 casos); los sufijos, las peticiones indirectas y los marcadores de control del contacto (2 casos); y las estructuras sintácticas que restringen el acto de habla, las fórmulas de tratamiento y la prosodia y el paralenguaje (1 caso). 